\title{
Periodic Hematopoiesis in Human Cyclic Neutropenia
}

\author{
D. Guerry, IV, D. C. Dale, M. Omine, S. Perry, and S. M. Wolfy \\ From the Laboratory of Clinical Investigation, National Institute of Allergy and \\ Infectious Diseases, and the Division of Cancer Treatment, National Cancer \\ Institute, Bethesda, Maryland 20014
}

\begin{abstract}
A B S T R A C T Human cyclic neutropenia is characterized by severe depression of blood neutrophil. levels approximately every 21 days. To investigate the mechanism of cyclic neutropenia four patients were studied with daily complete blood counts, serial bone marrow examinations, marrow reserve testing, serum muramidase determinations, $\mathrm{DF}^{32} \mathrm{P}$ granulocytokinetic studies, and, in one patient, in vivo $\left[{ }^{3} \mathrm{H}\right] \mathrm{TdR}$ labeling. Periodogram analysis of the serial blood counts in the latter patient and visual inspection of multiple cycles in the others revealed periodic fluctuations in the levels of blood neutrophils, monocytes, lymphocytes, reticulocytes, and platelets. Rhythmic changes in the morphologic and radioisotopic studies as well as the marrow reserve tests and muramidase measurements were consonant with a mechanism of periodic failure of marrow production rather than peripheral destruction. Human cyclic neutropenia is analogous to cyclic neutropenia in the grey collie dog and may be viewed as the consequence of cyclic hematopoiesis.
\end{abstract}

\section{INTRODUCTION}

Cyclic neutropenia in both human beings and grey collie dogs is characterized by the strikingly periodic occurrence of profound neutropenia. It has been recently recognized that the canine disease involves periodic fluctuations in all the formed elements of the blood-neutrophils, monocytes, lymphocytes, eosinophils, reticulocytes, and platelets (1). Periodic changes in monocyte levels (2-4) and platelet counts (5) have been noted in the human malady and the suggestion has been made that periodic hematopoiesis underlies this disease in both man and $\operatorname{dog}(6)$. To investigate the extent of the hematologic abnormalities in human

This work was presented in part at the Annual Meeting of the American Society of Hematology, Hollywood, Fla., 6 December 1972.

Received for publication 24 May 1973 and in revised form 23 July 1973. cyclic neutropenia and to define the mechanism of its production we have performed detailed studies of the peripheral blood counts and the formation and fate of blood cells in four patients. The present studies indicate that in man, as in the grey collie dog, cyclic fluctuations of all blood elements occur. Periodic marrow failure, perhaps at the pluripotential, or early committed, stem cell level, is causal.

\section{METHODS}

Patients. Two women, ages 67 and $23 \mathrm{yr}$ (patients 1 and 3 ), with symptoms strongly suggestive of childhoodonset cyclic neutropenia and two boys, ages 9 and $8 \mathrm{yr}$ (patients 2 and 4), with disease well documented from early childhood were the subjects of these studies. The patients were unrelated, and none had a family history of neutropenia. Except for periodic fevers, aphthous stomatitis, and occasional infections accompanying severe neutropenia (7), the patients were in good health. None had splenomegaly by either physical examination or technetium $\left({ }^{90} \mathrm{Tc}\right)$ scan. Patient 1 had a normal spleen removed before study without change in her disease.

Blood counts. Leukocyte, erythrocyte, and platelet counts were made on EDTA-anticoagulated samples using an electronic particle counter ${ }^{1}$ and standard techniques (8-10). 100-400 cell differential counts were done on air-dried, 'Wright's-stained peripheral blood smears. For reticulocyte counts, three drops of EDTA-anticoagulated blood and three drops of new methylene blue N (Brecher formula) ${ }^{2}$ were mixed for $10 \mathrm{~min}$ and air-dried smears made. The percentage of reticulocytes was determined by examining 1,000 erythrocytes in adjacent microscopic fields using a Miller disk $^{3}$ All samples were obtained between 8:00 and 9:00 a.m.

Statistical analysis of serial blood counts. Only patient 1 was available for study long enough for sufficient data to be collected to construct the Schuster periodogram to detect periodicity $(1,11,12)$. Daily neutrophil, monocyte, and lymphocyte counts were analyzed for 206 consecutive days with less than $5 \%$ missing observations. Consecutive erythrocyte, reticulocyte, platelet, basophil, and eosinophil counts were examined for 108 days with less than $3 \%$ miss-

${ }^{1}$ Coulter Counter Model Fn, Coulter Electronics, Inc., Fine Particle Group, Hialeah, Fla.

${ }^{2}$ Hartman-Leddon Company, Philadelphia, Pa.

: Bausch \& Lomb, Inc., Rochester, N. Y. 
ing observations. The significance of the largest peak of the periodogram was determined by the Fisher statistic $(g)$, which is the ratio of the height of this peak to the area between the periodogram and the horizontal axis $(1,13)$. Data from a normal volunteer studied over 89 consecutive days were identically analyzed for comparison (12).

Bone marrow. Aspirates of bone marrow were taken from the posterior iliac crest on 5 days of a single 21-day cycle in patient 1 . In each of the other patients from one to three aspirates were obtained during the neutropenic and recovery phases of a cycle. Differential cell counts of at least 500 nucleated cells were made on Wright's stained smears.

Marrow neutrophil reserves. Marrow reserves were tested in each patient during the neutropenic and recovery phases of several cycles. Base-line (preinjection) and hourly neutrophil counts were done for $6 \mathrm{~h}$ after intravenous infusion of $0.8 \mathrm{ng} / \mathrm{kg}$ of Salmonella abortus equi endotoxin (Lipexal ${ }^{4}$ ) and $200 \mathrm{mg}$ of hydrocortisone sodium succinate (Solu-Cortef ${ }^{5}$ ). Counts were also done before and 12,15 , and $18 \mathrm{~h}$ after intramuscular administration of $0.1 \mathrm{mg} / \mathrm{kg}$ of etiocholanolone. ${ }^{6}$ The maximum increase in the blood neutrophil count over baseline was used as a measure of the marrow reserve. The mean neutrophil count for all patients during neutropenia was $97.6 \pm 33.0 / \mathrm{mm}^{3}$ and during recovery was $1,838.1 \pm 319 / \mathrm{mm}^{3}$.

Tritiated thymidine $\left(\left[^{s} \mathrm{H}\right] \mathrm{TdR}\right)$ in vivo-labeling study. $70 \mu \mathrm{Ci} / \mathrm{kg}$ of $\left[{ }^{3} \mathrm{H}\right] \mathrm{TdR}{ }^{7}$ ( $\mathrm{sp}$ act $2.0 \mathrm{Ci} / \mathrm{mM}$ ) was administered intravenously to patient 1 during the neutropenic phase of a cycle and the recovery phase of the subsequent cycle. The appearance of ${ }^{3} \mathrm{H}$-labeled cells in the peripheral blood was monitored at frequent intervals by liquid scintillation counting and autoradiography (14). 20-ml samples of peripheral venous blood were dextran-dextrose-EDTA sedimented. Leukocyte-rich plasma was removed, centrifuged, and the leukocyte pellet subjected once or twice to brief (30 s) hypotonic lysis to remove erythrocytes. A few drops of the final leukocyte suspension in an equal volume of $10 \%(\mathrm{w} / \mathrm{v})$ bovine serum albumin ${ }^{8}$ was used to prepare smears for autoradiography. The rest of the leukocytes were frozen until all samples could be prepared for liquid scintillation counting. Cell recovery was in the range of $50-60 \%$ of the starting number and erythrocyte contamination was minor. After digestion with $1.0 \mathrm{ml}$ of NCS solubilizer, ${ }^{9}$ leukocyte pellets were dissolved in $12 \mathrm{ml}$ of a Biosolv (BBS-3) ${ }^{10}$-Liquiflour ${ }^{11}$-toluene cocktail and radioactivity counted with a liquid scintillation counter. ${ }^{12}$ To correct for the possibility of variable counting efficiency, reflecting erythrocyte contamination, a standard curve was prepared relating counting efficiency and absorbence at 400 nm. Using this curve, we corrected efficiency for every sample and found it to be between 40 and $50 \%$. Peripheral blood leukocyte radioactivity was expressed in $\mathrm{dpm} / 10^{7}$ leukocyte. Methanol-fixed smears for autoradiographs were prepared by the stripping method in a standard manner with Kodak AK-10 stripping film ${ }^{13}$ and exposed at $4^{\circ} \mathrm{C}$

"Dorsey Labs., Lincoln, Nebr.

- The Uipjohn Co., Kalamazoo, Mich.

- Sigma Chemical Co., St. Louis, Mo.

${ }^{7}$ Amersham/Searle Corp., Arlington Heights, Ill.

${ }^{8}$ Armour Pharmaceutical Co., Kankakee, Ill.

- Amersham/Searle Corp., Arlington Heights, Ill.

${ }^{10}$ Beckman Instruments, Inc., Fullerton, Calif.

${ }^{11}$ New England Nuclear Corp., Boston, Mass.

12 Packard Tri-Carb Scintillation Spectrometer, Model

3375, Packard Instrument Co., Inc., Downers Grove, I1l.

${ }^{13}$ Eastman Kodak Co., Rochester, N. Y. for 13 wk before development. Cells with more than 4-5 grains were scored as labeled. Background was negligible and morphological identification of each cell type was not difficult. To obtain the percentage of labeled cells (labeling index) the following number of cells were counted: polymorphonuclear leukocytes (PMNs) ${ }^{14}$ more than 500 (when abundant); monocytes, more than 100 ; lymphocytes, more than 2,000; and eosinophils, more than 50. Differential counts were performed separately on Wright-Giemsastained smears. The total number of labeled cells of each type was calculated by the following equation:

Total number of labeled cells $/ \mathrm{mm}^{3}=$ leukocyte count $/ \mathrm{mm}^{3}$ $\times \%$ of differential count $\times$ labeling index.

Serum muramidase (lysozyme). Serum was obtained from blood samples allowed to clot at room temperature for $2 \mathrm{~h}$, then frozen at $-20^{\circ} \mathrm{C}$ until used. Muramidase concentrations were determined by the turbidimetric method of Litwack (15), using a Micrococcus lysodeikticus substrate $^{15}$ and expressed as micrograms per milliliter of egg white standard.

Diisopropylfuorophosphate $\left(D F^{s z} P\right)$ leukokinetics. In each patient neutrophil half-disappearance time (PMN $\left.\mathrm{t}_{1}\right)$ and distribution were measured with a modification of the methods devised by Athens and associates (16-19). Approximately $10 \%$ of the blood volume was collected in a plastic bag containing acid-citrate-dextrose (ACD) anticoagulant. ${ }^{16}$ After addition of $50-100 \mu \mathrm{Ci}$ of $\mathrm{DF}^{32} \mathrm{P}$ (footnote 17) and mixing for $45 \mathrm{~min}$, blood was reinfused. $20-\mathrm{ml}$ blood samples were obtained from the bag before reinfusion, and heparinized samples from the antecubital veins of patients were drawn at $1,3,6,12$, and $24 \mathrm{~h}$. Granulocytes were isolated from these blood samples by the Ficoll ${ }^{18}$-sodium diatrizoate (Hypaque) ${ }^{19}$ method of Boyum $(19,20)$. The leukocytes of the final cell preparation were regularly greater than $95 \%$ PMNs. Overall recovery of PMNs was usually $40-60 \%$.

After counting the cells with an electronic particle counter, they were digested with $0.2 \mathrm{~N} \mathrm{NaOH}$ at $60^{\circ} \mathrm{C}$ and acidified with $10 \%$ acetic acid. This material was solubilized in the above-mentioned toluene-phosphor system and radioactivity measured with a liquid scintillation counter. ${ }^{20}$ The specific activity for each sample was expressed as counts per minute per cell. The slope and $t_{\frac{1}{2}}$ for the specific activity curves were calculated by the methods of least squares (21). The total body, marginal, and circulating neutrophil pools and neutrophil turnover rates were measured by extrapolating the specific activity decay curves to time zero and applying the formulae of Cartwright, Athens, and Wintrobe (17). All curves were of the " $C$ " type described by Athens et al. (18). The extrapolated time zero did not differ significantly from that estimated from the 15-min or 1-h specific activity values and pool sizes measured by either method were approximately the same.

${ }^{14}$ Abbreviations used in this paper: $\mathrm{DF}^{32} \mathrm{P}$, diisopropylfluorophosphate; ${ }^{3} \mathrm{H}-\mathrm{TdR}$, tritiated thymidine; PMN, polymorphonuclear leukocyte.

${ }^{15}$ Worthington Biochemical Corp., Freehold, N. J.

${ }^{16}$ Fenwal Laboratories, Morton Grove, Ill.

${ }^{17}$ The Radiochemical Centre, Amersham, England.

${ }^{18}$ Pharmacia, Uppsala, Sweden.

${ }^{10}$ Winthrop Laboratories, New York.

${ }^{20}$ Beckman Liquid Scintillation Spectrometer, Model ISS250, Beckman Instruments, Inc., Fullerton, Calif.

Human Cyclic Neutropenia 

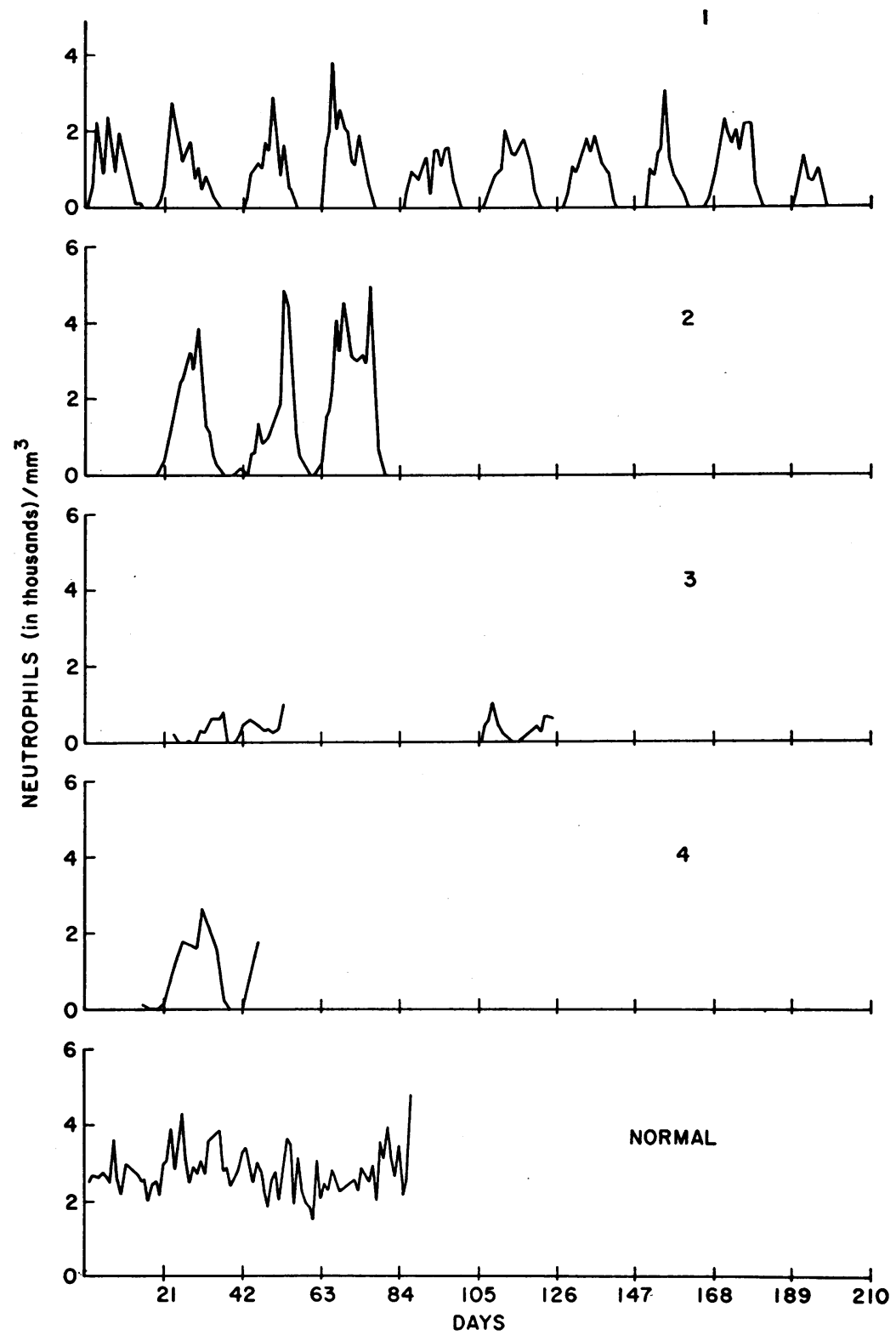

FIgURE 1 Circulating neutrophil counts over 25-200 days in 4 patients with cyclic neutropenia and a normal volunteer.

\section{RESULTS}

Blood counts. The pattern of fluctuation of the neutrophil counts of the four patients are compared to a series of daily counts obtained in a normal volunteer (Fig. 1). The strikingly periodic appearance of profound neutropenia at approximately 21 -day intervals is easily seen. While only three cycles in patient 3 and one cycle in patient 4 are shown, multiple serial neutrophil counts made during at least $3 \mathrm{yr}$ of repeated studies, have made the diagnosis of cyclic neutropenia unequivocal in each patient. Patients 1,3 , and 4 also demonstrate the mild to moderate chronic neutropenia characteristic of this disease (2). No obvious cycling of the neutrophil count is apparent in the sequence obtained in the normal volunteer.

To explore the possibility of a broader hematopoietic defect in this disease, daily leukocyte, differential, platelet, erythrocyte, and reticulocyte counts were done for 107-206 consecutive days in patient 1 (Fig. 2). Visual inspection of the graphic data demonstrates 


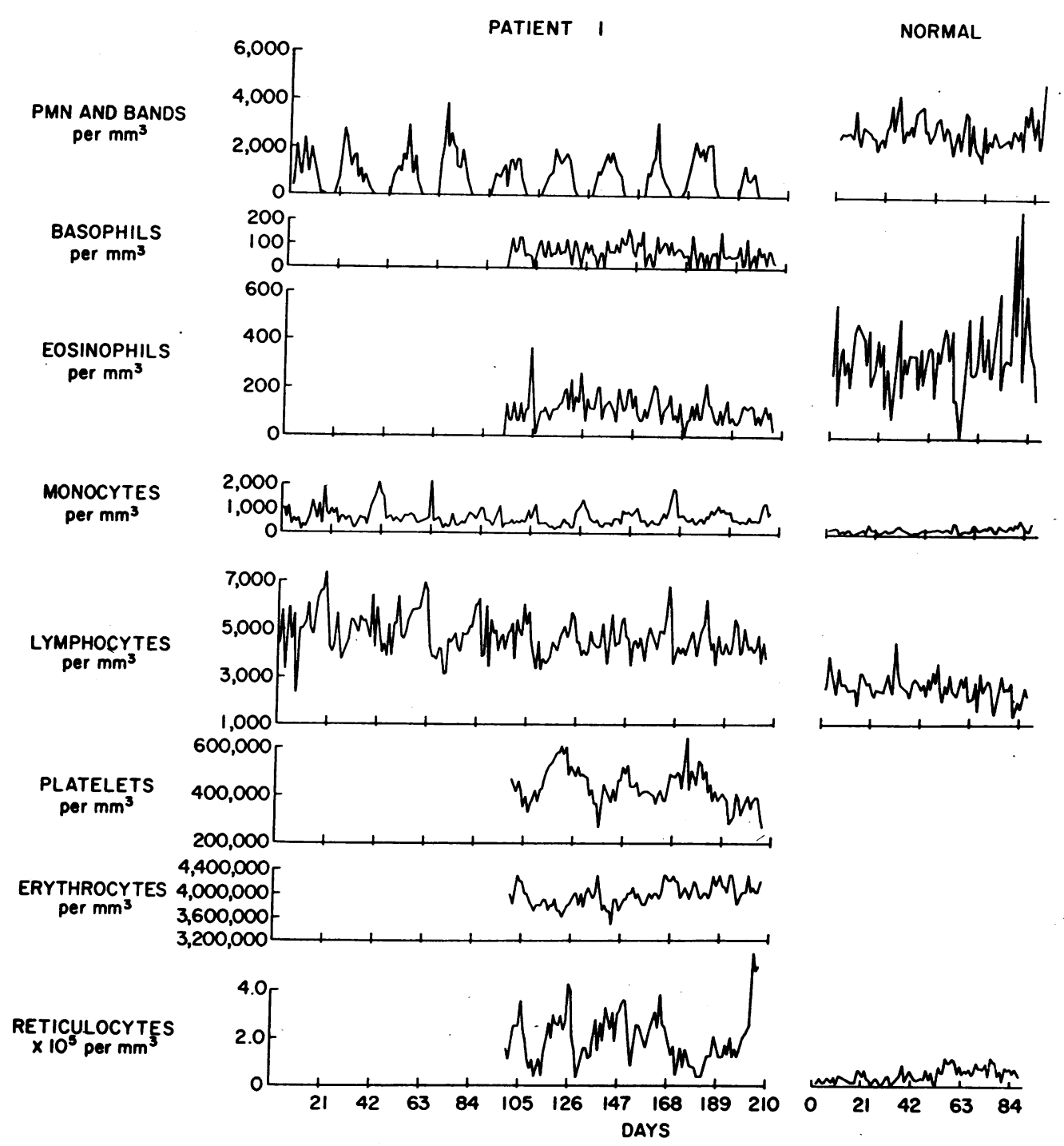

Figure 2 Peripheral blood counts in human cyclic neutropenia (patient 1) contrasted to a series in a normal volunteer. Cyclic fluctuation is apparent only in the neutrophil, monocyte, lymphocyte, platelet, and reticulocyte counts of patient 1 .

periodic oscillation of monocytes, lymphocytes, platelets, and reticulocytes. No cycling is apparent in the counts of the eosinophils, basophils, or erythrocytes.

To demonstrate the interrelationships between the counts of the different cell types arithmetic mean counts for corresponding days of 5-10 successive 21-day cycles in patient 1 were plotted (Fig. 3 ). The mean neutrophil count on day 2 of 10 successive cycles is zero (day $1=$ the day on which the peripheral neutrophil count is less than $250 / \mathrm{mm}^{3}$ ). At this time, the mean reticulocyte count is maximal and successive peaks of lymphocytes, monocytes, neutrophils, and, possibly, platelets occur. Thus, for each cell type the period is the same, approximately 21 days, but the phase is different.

Construction of the Schuster periodogram (Fig. 4) for data collected in patient 1 documents the periodicity apparent in the raw data. The peaks in the periodogram are a measure of the strength of periodicity at a particular period length-42,21, 10.5 days, and so on. The neutrophil peak at 20.6 days, the monocyte and lymphocyte peak at 21.1 days, the platelet peak at 27.0 days, and the reticulocyte peak at 21.4 days are all highly significant $(P<0.001)$. For eosinophils, basophils, and erythrocytes a 21-day peak is seen but the periodogram is so noisy that statistical significance is 

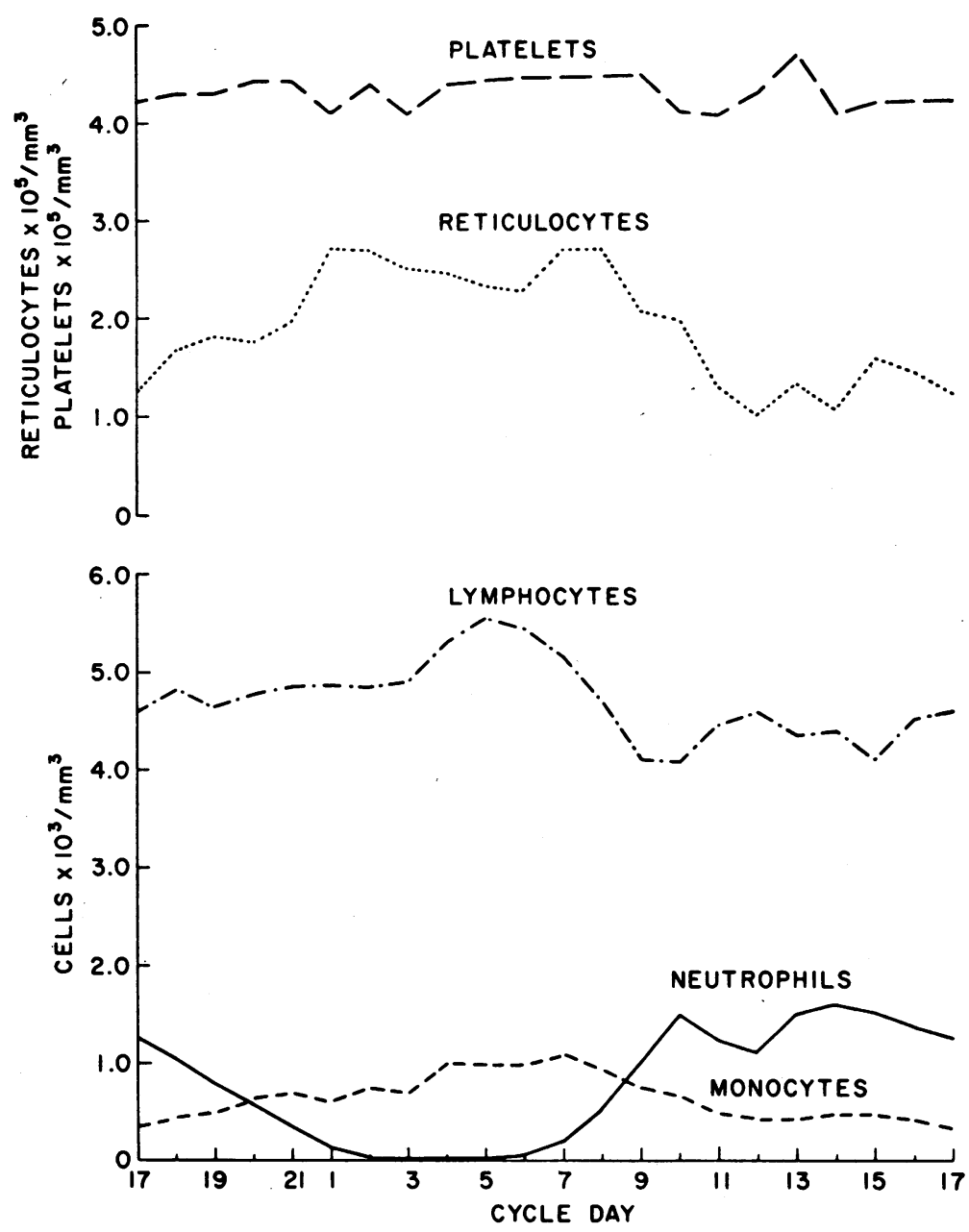

FIgURE 3 Composite 21-day cycle in human cyclic neutropenia (patient 1). Arithmetic mean cell counts for corresponding days of 5-10 successive 21-day cycles are plotted.

not achieved. No periodicity was demonstrated in the counts of the normal volunteer.

Periodogram analysis of the other patients was impossible, because long-term sequential data were not available. However, visual inspection of many partial and single cycles suggests that all peripheral blood cells cycle in the same manner as those of patient 1 .

Bone marrow. In Fig. 5, the differential counts of the bone marrow aspirates and the simultaneously occurring peripheral blood neutrophil cycle are depicted for one cycle in patient 1 . During the peripheral blood neutropenic phase, marrow PMNs are absent, but at this time a wave of myelopoiesis, successively made up of myeloblasts, promyelocytes, myelocytes, and metamyelocytes and bands, sweeps through the marrow. By the time peripheral neutrophil recovery is well established, at cycle days 12-14, earlier myeloid precursors (promyelocytes and myelocytes) are on the wane, setting the stage for the subsequent development of neutropenia. Examination of the bone marrows of the other patients at less frequent intervals discloses morphology commensurate with the phase of the myelopoietic wave. Thus, in all patients bone marrow sampling in the late neutropenic phase shows a paucity of PMNs and bands, and plentiful earlier precursors. Sampling at the midpoint of the recovery phase shows just the opposite proportion of mature and immature granulocytes.

Marrow reserves. Marrow neutrophil reserves, as measured by the increase in peripheral neutrophils, to etiocholanolone, endotoxin, and a glucocorticoid (22, 23) were tested during neutropenia and recovery (not necessarily in the same cycle) in each patient (Fig. 6). During neutropenia, negligible or no reserves were detected in any patient. During peripheral neutrophil recovery, normal or near normal reserves to etiocho- 

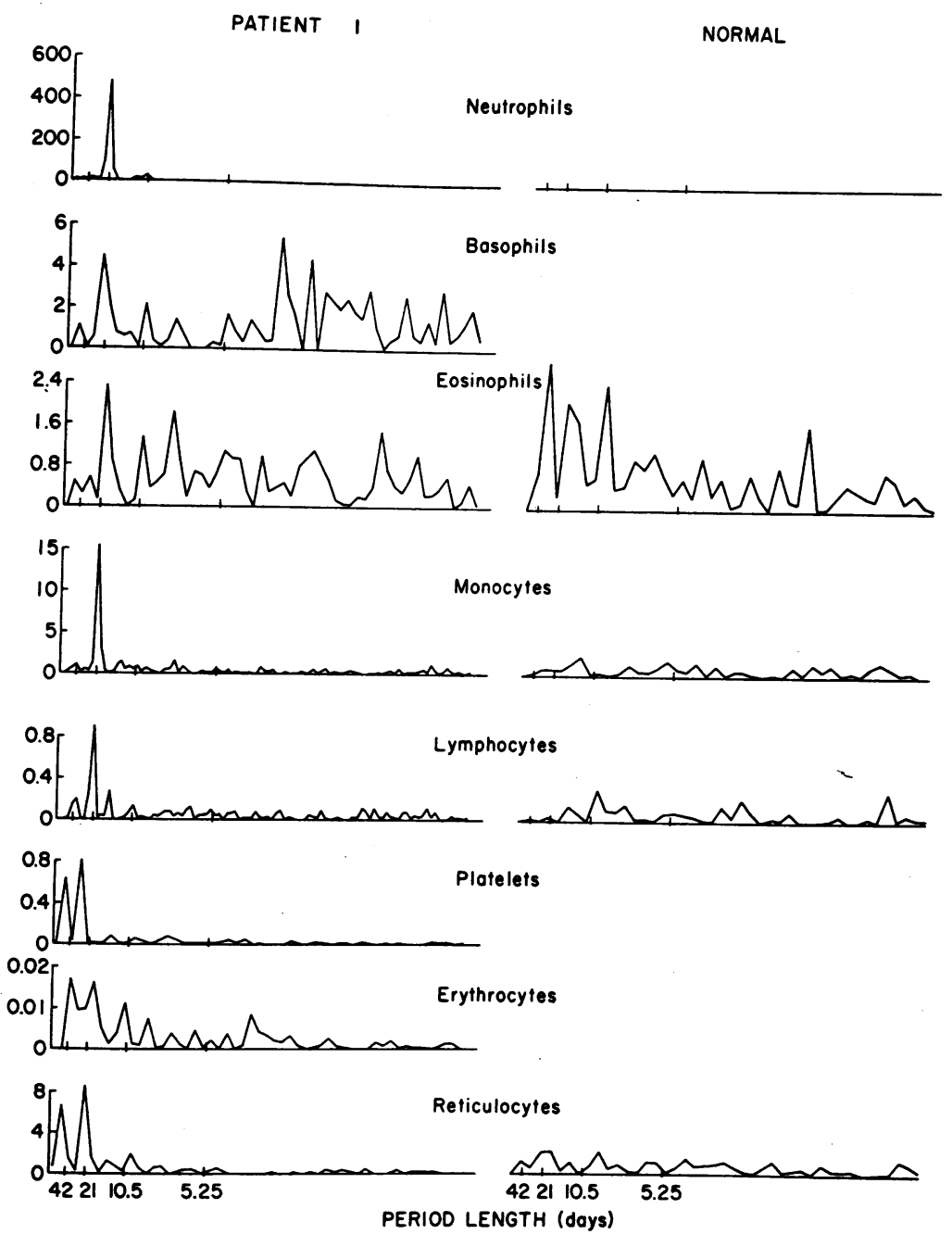

FIGURE 4 Periodograms of serial blood counts in human cyclic neutropenia (patient 1) and a normal volunteer. Significant periodicity is seen only in the neutrophil, monocyte, lymphocyte, platelet, and reticulocyte counts of patient 1 .

lanolone $\left(2,600\right.$ or more granulocytes $/ \mathrm{mm}^{3}$, [24]) and $/$ or endotoxin $\left(2,000\right.$ or granulocytes $\left./ \mathrm{mm}^{3}[25]\right)$ were established in three patients (patients 1,2, and 4). Although the neutrophil response to these two agents during the recovery phase was far greater than during neutropenia for patient 3 , the patient with the most marked neutropenia, it did not approach the normal range. In all patients the neutrophil response to the acute administration of hydrocortisone roughly paralleled that of the other agents.

In vivo $\left[{ }^{3} \mathrm{H}\right] T d R$ labeling. In patient $1,\left[{ }^{3} \mathrm{H}\right] \mathrm{TdR}$ was administered on day 6 of a cycle and day 14 of the subsequent cycle. After labeling during the late neutropenic phase the peak of radioactivity in peripheral blood leukocytes appeared on day 12 ( 6 days later). Labeling on day 14 , when peripheral neutrophil recovery was well established, resulted in a far smaller peak at 6 days. Autoradiographic analysis (Fig. 7) showed the first peak to be made up primarily of labeled neutrophils and the second to be almost entirely devoid of these cells.

Serum muramidase. Frequent determinations of serum muramidase were done for at least one cycle in each patient. Fig. 8 demonstrates the pattern of muramidase fluctuation with the simultaneously occurring monocyte and neutrophil cycles in patient 4 . For each patient, the pattern of a rising muramidase level with increasing peripheral monocytes before the return of neutrophils was maintained. The enzyme fell by the middle of the neutrophil recovery phase and paralleled the falling monocyte count. 


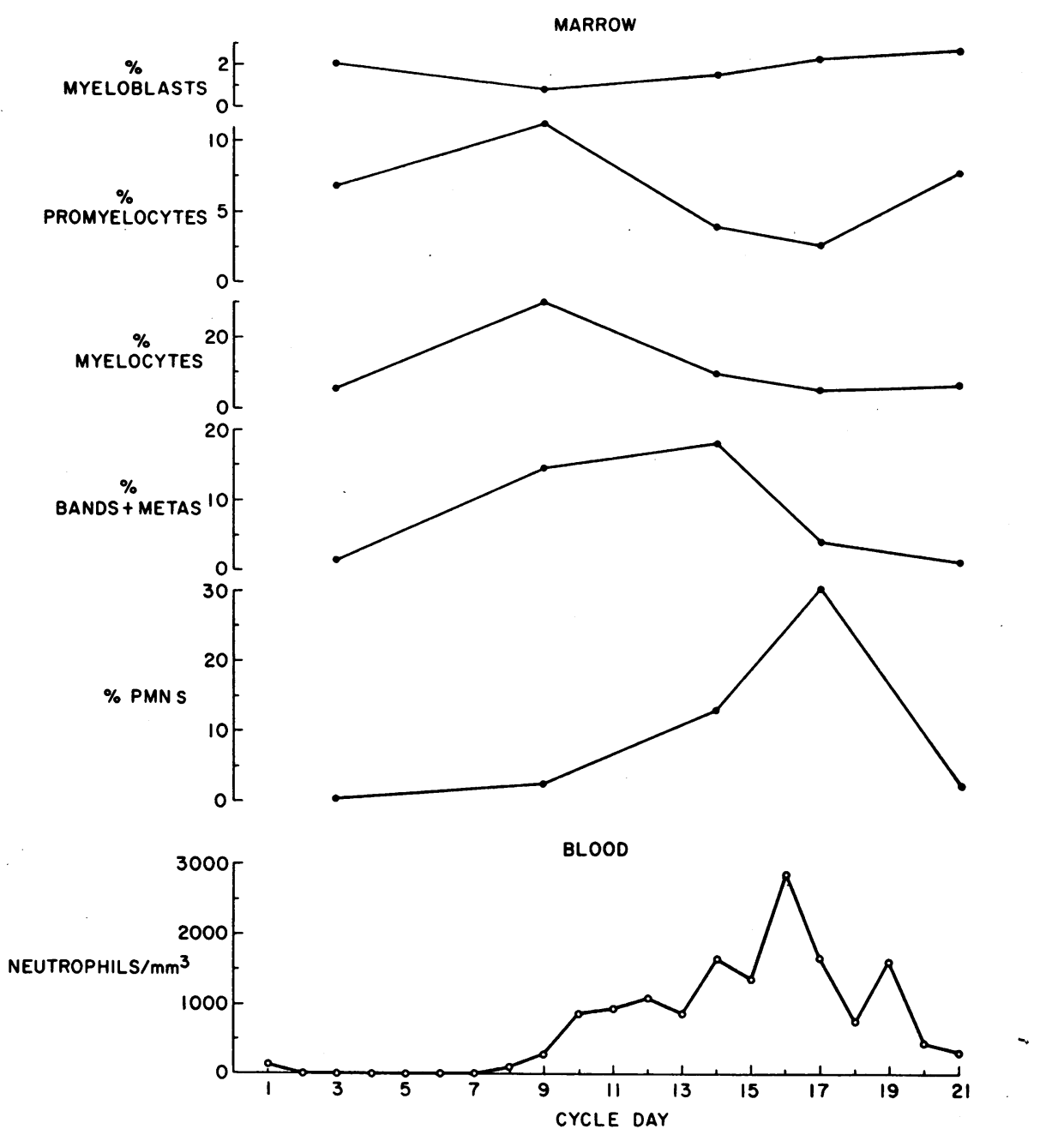

Figure 5500 cell bone marrow differential counts in human cyclic neutropenia (patient 1) over one cycle (upper five panels) and the simultaneous absolute peripheral neutrophil count (bottom panel).

Leukokinetic studies. In each patient a neutrophil blood half-time was obtained just before the development of neutropenia by following the disappearance of in vitro $\mathrm{DF}^{32} \mathrm{P}$-labeled autologous neutrophils (Table I). In the four patients studied on cycle days $15,17,18$, and 20 , neutrophil $\mathrm{t}$ was normal or slightly prolonged. The mean for our patients was $8.5 \mathrm{~h}$, compared to 6.6 $h$ in normals (26). Blood granulocyte pool sizes-circulating, marginal, and total blood granulocyte poolswere generally small and probably reflect the degree of peripheral neutropenia.

\section{DISCUSSION}

These studies demonstrate that human cyclic neutropenia is remarkably periodic. The finding in the patient most thoroughly studied that neutrophils, mono- cytes, lymphocytes, platelets, and reticulocytes all cycle with strict periodicity suggests that this disease in man should be viewed as cyclic hematopoiesis, not merely as cyclic neutropenia. That the period length is approximately the same for each cell type and that each cell type follows an entirely separate pattern of fluctuation suggest that production of all marrow elements is simultaneously disturbed at one point in the cycle. If marrow production fails at an early precursor cell level between cycle days 12 and 16, at about the zenith of peripheral neutrophil recovery, and subsequently resumes, then successive peaks of each cell type should appear in the peripheral blood. The time and order of appearance of each cell type should reflect its marrow transit time. The invariable appearance of increasing numbers of reticulocytes at 4-5 days after 
cycle day 16 and of neutrophils 9-11 days after this time (Fig. 3) is in keeping with what is known of the time required for these cells to transit the marrow proliferating and maturing pools $(27,28)$. From our data, it would seem that the time required to generate a blood monocyte from early precursors is intermediate, 6-8 days, but little data in humans bear on this point. This time-course would appear to be a reasonable one since monocytes probably arise from the same committed stem cell as the neutrophil $(29,30)$, but do not reside in any marrow storage pool for an appreciable period of time (31). In addition, the return of monocytes often precedes by a few days the return of granulocytes after periods of marrow suppression. The model of monocytopoiesis recently constructed by Meuret (31) giving a marrow to blood transit time of $56 \mathrm{~h}$ is considerably less than our data would indicate, but this time span represents an absolute minimum. Because the precise time of onset of marrow recovery cannot be pinpointed, a more exact transit time cannot be designated for each cell type. A platelet peak fixed in relationship to the other cell types is not apparent in our data, but in the dog the platelet is invariably the first element to increase (1).

Unfortunately, similar detailed investigation of the other three patients could not be performed because of their unavailability for long-term study. Thus the data are not adequate to permit a categorical statement that all blood elements cycle, but that this obtains is strongly suggested by examination of many short-term observations in these patients and corroborated by the common observation of cyclic monocyte fluctuations (2-4) and the single report of periodic platelet oscillations (5) in human cyclic neutropenia. To convincingly demonstrate periodicity requires a long-term, equally spaced series of observations with few gaps. Such data must be examined by statistical methods as well as visual inspection (12), a goal often difficult to achieve with patients.

The balance of the data collected in this group of patients relates directly to the marrow myeloid events determining the peripheral blood cycle. Marrow morphological studies in our patients are in agreement with those of others $(2,32)$ and demonstrate a myeloid wave made up of increasingly mature granulocyte precursors preceding the increasing peripheral blood neutrophil counts. That morphological marrow recovery is accompanied by functional recovery of the marrow storage pool of bands and polymorphonuclear leukocytes as well as by population of the peripheral blood is supported by the results of the bone marrow reserve tests. Exhaustion of the marrow reserves was seen with the descending limb of the blood neutrophil count.

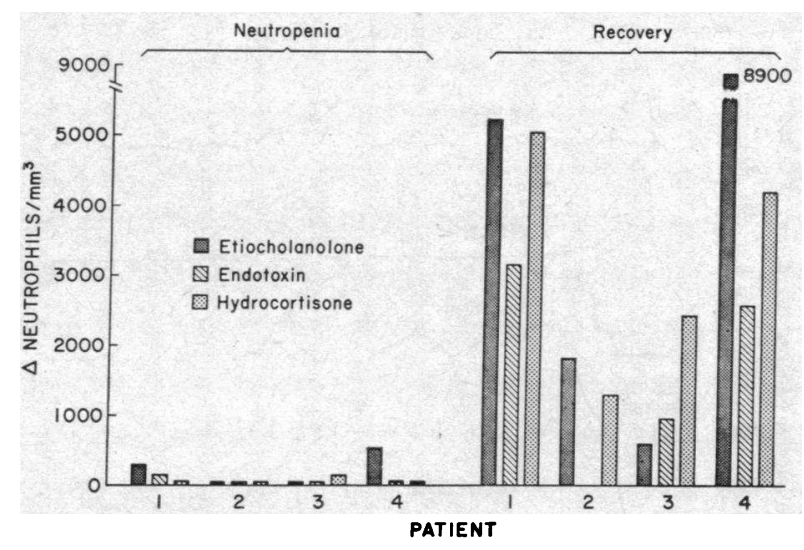

Figure 6 Bone marrow neutrophil reserves to three agents during neutropenia and recovery in four patients with human cyclic neutropenia. Endotoxin was not used in patient 2 during the recovery phase.

Serum muramidase levels rise during midneutropenia and peak just before the recovery of the peripheral neutrophil count and would seem to reflect marrow granulocytopoietic activity (33). That this enzyme parallels the monocyte count may indicate an important contribution by these cells to the serum enzyme levels.

These morphological and functional data indicate that fluctuation in blood neutrophils is secondary to fluctuating rates of cell production. Marrow production is turned on during neutropenia and switched off after the peripheral blood neutrophil count is reconstituted. That neutrophil production is qualitatively normal during the late neutropenic period is demonstrated by the first in vivo $\left[{ }^{3} \mathrm{H}\right] \mathrm{TdR}$-labeling study. In a similar investigation Meuret and Fliedner (32) have shown, by labeling slightly later in the cycle, a shortened com-

TABLE I

Leukokinetic Studies in Human Cyclic Neutropenia

\begin{tabular}{|c|c|c|c|c|c|c|}
\hline Patient & Cycle & $t \frac{1}{2} *$ & C P & MGP\& & TBGP $\|$ & GTR I \\
\hline & day & $h$ & $\times 10^{7} / \mathrm{kg}$ & $\times 10^{7} / \mathrm{kg}$ & $\times 10^{i} / \mathrm{kg}$ & $\begin{array}{l}\times 10^{7} / \\
k g / \text { day }\end{array}$ \\
\hline 1 & 15 & 8.4 & 14.8 & 24.4 & 39.2 & 79.0 \\
\hline 2 & 17 & 8.7 & 10.3 & 37.0 & 47.3 & 90.5 \\
\hline 3 & 18 & 7.3 & 14.3 & 52.6 & 66.9 & 152.8 \\
\hline 4 & 20 & 9.5 & 2.95 & 7.35 & 10.3 & 18.2 \\
\hline Mean & & 8.5 & 10.6 & 30.9 & 40.9 & 85.1 \\
\hline $\pm 1 \mathrm{SE}$ & & 0.46 & 2.7 & 9.6 & 11.7 & 27.6 \\
\hline Normals** & & 6.6 & 37.1 & 33.3 & 65.0 & 179.9 \\
\hline $\pm 1 \mathrm{SE}$ & & 1.16 & 11.1 & 16.0 & 22.4 & 74.3 \\
\hline
\end{tabular}

* Neutrophil half-disappearance time.

¥ Circulating granulocyte pool.

\& Marginal granulocyte pool.

|| Total blood granulocyte pool.

I Granulocyte turnover rate.

** From Athens et al. (26). 


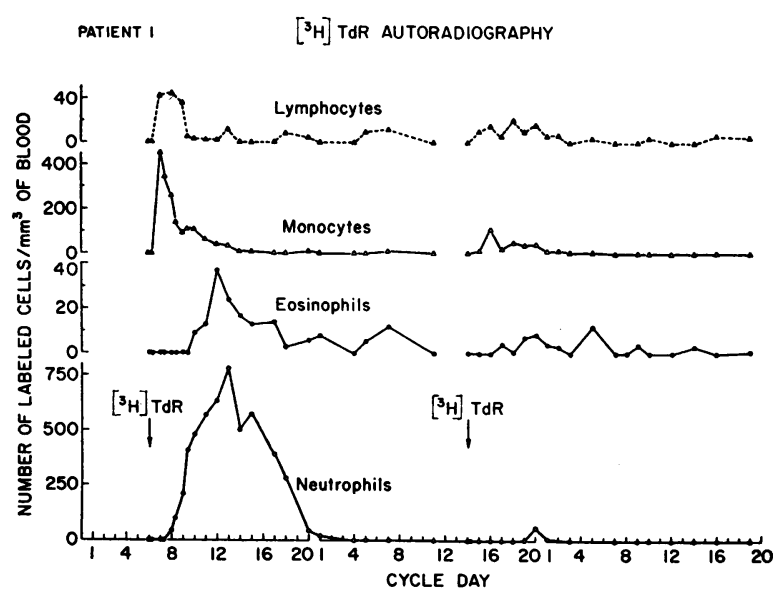

Figure 7 Autoradiographic identification of in vitro $\left[{ }^{3} \mathrm{H}\right]-$ TdR-labeled cells after in vivo $\left[{ }^{3} \mathrm{H}\right] \mathrm{TdR}$ labeling on cycle days 6 and 14 .

partment transit time for granulocytes in the maturation pool with the consequent earlier appearance of labeled neutrophils in the peripheral blood. Their data indicate that at one point in the cycle the granulocytopoietic system in this disease is normally responsive to the stress of neutropenia (34). That our patient did not abbreviate the marrow granulocyte transit time may simply reflect labeling earlier in the neutropenic phase. Labeling during the midpoint of neutrophil recovery reveals essentially no neutrophil generative activity and little eosinophil, monocyte, or lymphocyte labeling.

That periodic peripheral destruction of neutrophils is not involved in this disease is supported by the normal blood half-life of neutrophils just before the development of neutropenia and by the relatively slow rate of decline ( 3 or 4 days) of the neutrophil count with the onset of neutropenia. Unfortunately, there are too few neutrophils during the neutropenia period to perform neutrophil survival studies with autologous cells, and transfusion studies are not justified. In the dogs with cyclic neutropenia, however, infused normal cells survive normally during the neutropenic period (6). The dog data do not suggest that a shift of cells to the marginal pool is the cause of the neutropenia. Dienard and Page have reported normal granulocyte blood half-time in two patients with cyclic neutropenia, although they did not mention the cycle day on which the studies were done (35). Analysis of the granulocyte turnover rate in the patient studied by Meuret and Fliedner also argues against peripheral destruction (32). A single report of cyclic neutropenia with a prominent component of granulocyte destruction has appeared but this patient is atypical in many ways (36). The normal muramidase levels at the onset of neutropenia are also supportive of the concept that peripheral neutrophil destruction (33) is not involved in this disease. The muramidase fluctuations probably reflect the periodic increase in both monocyte and neutrophil production.

Our data in human cyclic neutropenia are remarkably analogous to that obtained in detailed studies of the hematopoietic system in the grey collie dog $(1,6)$. Periodic oscillations in the levels of each of the peripheral blood cell types, in marrow morphology, marrow reserve responses, and muramidase levels characterize both the human and canine diseases. Normal blood granulocyte survival is also found in both. While the period length of the cycle in the dog is shorter than in man, 12 days as opposed to 21 , this difference is determined by the shorter marrow to blood transit time $(37,38)$. The heritable nature of the disease and the associated pigmentary changes in the dog (39) are not apparent in affected human beings.

While our data in human beings and grey collie dogs indicate that cyclic hematopoiesis, or cyclic inhibition of hematopoiesis, is the proximate cause of the periodic peripheral blood changes and that the locus of the hematopoietic defect may be at the pluripotential, or committed, stem cell level, it does not demonstrate the causa causans of cyclic neutropenia. Possible mechanisms to explain the derangement basic to this disease include exaggerated feedback control $(40,41)$, abnormalities of stem cell function or cycling of short-
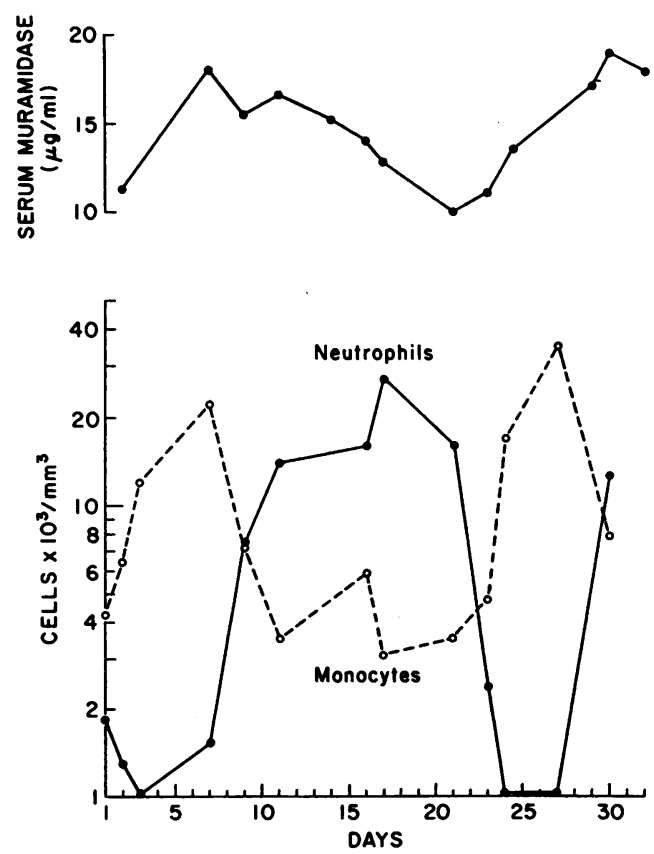

Figure 8 Serum muramidase and serial peripheral neutrophil and monocyte counts for 1 cycle in human cyclic neutropenia (patient 4 ). 
range $(42,43)$ or long-range humoral stimulators or inhibitors. Cyclic increases in urinary colony-stimulating activity, a possible granulopoietin (29), during late neutropenia and the early recovery phase in both grey collie dogs (44) and man, ${ }^{21}$ and concomitant cycling of erythropoietin (45) in the canine disease indicate that disturbance of these regulators may be of possible pathogenetic importance. On the other hand, the recent demonstration that normal, noncyclic hematopoiesis can be restored in the grey collie by allogeneic bone marrow transplantation from a normal collie is evidence in favor of a defect of early precursor cells (46). The close congruity of the human and dog disease should allow, through manipulation of the canine model, the generation of important data on the regulation of both nor$\mathrm{mal}$ and abnormal hematopoiesis in both speices.

\section{ACKNOWLEDGMENTS}

We thank Dr. David W. Alling for his statistical analysis of the data, and Mrs. Rhoda Hubert, Ms. Ada E. Brooks, and Mr. Dwight E. Bagley for their expert technical assistance.

\section{REFERENCES}

1. Dale, D. C., D. W. Alling, and S. M. Wolff. 1972. Cyclic Hematopoiesis: the mechanism of cyclic neutropenia in grey collie dogs. J. Clin. Invest. 51: 2197.

2. Page, A. R., and R. A. Good. 1957. Studies on cyclic neutropenia. Am. J. Dis. Child. $94: 623$.

3. Videbaek, A. 1962. Cyclic neutropenia: report on three cases. Acta Mcd. Scand. 172: 715 .

4. Coutel, Y., H. Morel, and G. Thomet. 1963. Neutropénie cyclique chez un enfant de 6 ans. Nouv. Rev. Fr. Hematol. 3: 482.

5. Liu, Y. K., W. Adams, and L. W. Sullivan. 1970. Periodic neutropenia associated with periodic fluctuations in platelet counts. Clin. Res. 18: 409. (Abstr.)

6. Dale, D. C., S. B. Ward, H. R. Kimball, and S. M. Wolff. 1972. Studies of neutrophil production and turnover in grey collie dogs with cyclic neutropenia. $J$. Clin. Invest. $51: 2190$.

7. Geelhoed, G. W., M. A. Kane, D. C. Dale, and S. A. Wells. 1973. Colonic perforation in cyclic neutropenia: report of a survivor with peritonitis and clostridial septicemia. J. Pediatr. Surg. 8: 379.

8. Richar, W. J., and E. S. Breakell. 1959. Evaluation of electronic particle counter for counting white blood cells. Am. J. Clin. Pathol. 31: 384.

9. Brecher, G., M. A. Schneiderman, and G. Z. Williams. 1956. Evaluation of electronic red blood cell counter. Am. J. Clin. Pathol. 26: 1439.

10. Bull, B. S., M. A. Schneiderman, and G. Brecher. 1965. Platelet counts with the Coulter counter. Am. J. Clin. Pathol. $44: 678$.

11. Hannan, E. J. 1960. Estimation of the spectral density and distribution functions. In Time Series Analysis. Methuen \& Co. Ltd., London. 52.

${ }^{21}$ Guerry, D., D. C. Dale, and S. M. Wolff, Data to be published.
12. Dale, D. C., D. W. Alling, and S. M. Wolff. 1973. Application of time series analysis to serial blood neutrophil counts in normal individuals and patients receiving cyclophosphamide. Br. J. Haematol. 24: 57.

13. Fisher, R. A. 1929. Tests of significance in harmonic analysis. Proc. R. Soc. Lond. A Math. Phys. 125: 54.

14. Perry, S., J. H. Moxley, III, G. H. Weiss, and M. Zelen. 1966. Studies of leukocyte kinetics by liquid scintillation counting in normal individuals and in patients with chronic myelocytic leukemia. J. Clin. Invest. $45: 1388$.

15. Litwack, G. 1955. Photometric determination of lysozyme activity. Proc. Soc. Exp. Biol. Med. 89: 401.

16. Athens, J. IV., A. M. Mauer, H. Ashenbrucker, G. E. Cartwright, and M. M. Wintrobe. 1959. Leukokinetic studies. I. A method for labeling leukocytes with diisopropylfluorophosphate $\left(\mathrm{DEP}^{32}\right)$. Blood J. Hematol. $14: 303$.

17. Cartwright, G. E., J. W. Athens, and M. M. Wintrobe, 1964. The kinetics of granulopoiesis in normal man. Blood J. Hematol. 24 : 780.

18. Athens, J. W., O. P. Haab, S. O. Raab, D. R. Boggs, H. Ashenbrucker, G. E. Cartwright, and M. M. Wintrobe. 1965. Leukokinetic studies. XI. Blood granulocyte kinetics in polycythemia vera, infection, and myelofibrosis. J. Clin. Invest. 44: 778.

19. Dale, D. C., and S. M. Wolff, 1973. Studies of the neutropenia of acute malaria. Blood J. Hematol. 41: 197.

20. Boyum, A. 1968. Isolation of mononuclear cells and granulocytes from human blood. Scand. J. Clin. Lab. Invest. Suppl. $21(97): 77$.

21. Aitken, A. C. 1957. The method of least squares: multivariate correlation: polynomial and harmonic regression. In Statistical Mathematics. Oliver \& Boyd L.td., Edinburgh. 8th edition. 106.

22. Cream, J. J. 1968. Prednisolone-induced granulocytosis. Br. J. Haematol. 15 : 259.

23. Strausz, I., E. Kékes, and A. Szebeni. 1965. Mechanism of prednisolone-induced leukocytosis in man. Acta Haematol. (Basel). 33: 40.

24. Kimball, H. R., J. M. Vogel, S. Perry, and S. M. Wolff. 1967. Quantitative aspects of pyrogenic and hematologic responses to etiocholanolone in man. $J$. Lab. Clin. Med. 69: 415.

25. Mechanic, R. C., E. Frei, III, M. Landy, and W. W. Smith. 1962. Quantitative studies of human leukocytic and febrile response to single and repeated doses of purified bacterial endotoxin. J. Clin. Invest. 41: 162 .

26. Athens, J. W., O. P. Haab, S. O. Raab, A. M. Mauer, H. Ashenbrucker, G. E. Cartwright, and M. M. Wintrobe. 1961. Leukokinetic studies. IV. The total blood, circulating and marginal granulocyte pools and the granulocyte turnover rate in normal subjects. J. Clin. Invest. 40: 989.

27. Cronkite, E. P., and T. M. Fliedner. 1964. Granulocytopoiesis. N. Engl. J. Med. 270: 1347 and 1403.

28. Craddock, C. G. 1972. Granulocyte kinetics. In Hematology. W. J. Williams, E. Beutler, A. J. Erslev and R. W. Rundles, editors. McGraw-Hill Book Company, New York. 593.

29. Bradley, T. R., and E. Metcalf. 1966. The growth of mouse bone marrow cells in vitro. Aust. J. Exp. Biol. Med. Sci. $44: 287$. 
30. Senn, J. S., E. A. McCulloch, and J. E. Till. 1967. Comparison of colony-forming ability of normal and leukemic human marrow in cell culture. Lancet. 2: 597.

31. Von Meuret, G. 1972. Monozytopoese und Kinetik der Blutmonozyten beim Menschen. Blut Z. Gesamte Blutforsch. 24: 337.

32. Von Meuret, G., and T. M. Fliedner. 1970. Zellkinetik der Granulopoese und des Neutrophilensystems bei einem Fall von zyklischer Neutropenie. Acta Hacmatol. (Basel). $43: 48$.

33. Fink, M. E., and S. C. Finch. 1968. Serum muramidase and granulocyte turnover. Proc. Soc. Exp. Biol. Med. $127: 365$.

34. Chikkappa, G., and M. L. Greenberg. 1973. Neutrophil kinetics in neutropenia and neutrophilia. Clin. Res. 21 : 549. (Abstr.)

35. Deinard, A. S., and A. R. Page. 1970. An improved method for performing neutrophil survival studies. Blood J. Hematol. 36 : 98.

36. Brubaker, L. H. 1971. Cyclical neutropenia (CN) associated with increased neutrophil (N) destruction and serum neutrophil lytic activity. Blood J. Hematol. 38: 813. (Abstr.)

37. Maloney, M. A., and H. M. Patt. 1968. Granulocyte transit from bone marrow to blood. Blood J. Hematol. $31: 195$.

38. Boggs, D. R., J. W. Athens, G. E. Cartwright, and M. M. Wintrobe. 1965. Leukokinetic studies. IX. Ex- perimental evaluation of a model of granulopoiesis. J. Clin. Invest. $44: 643$.

39. Lund, J. E., G. A. Padgett, and R. L. Otto. 1967. Cyclic neutropenia in grey collie dogs. Blood J. Hcmatol. 29 : 452.

40. Morley, A., E. A. King-Smith, and F. Stohlman, Jr. 1970. The oscillatory nature of hematopoiesis. In Hematopoietic Cellular Proliferation. F. Stohlman, Jr., editor. Grune \& Stratton, Inc., New York. 3.

41. Morley, A. 1970. Periodic diseases, physiologic rhythms and feedback control-a hypothesis. Australas. Ann. Med. 19: 244

42. Rytömaa, T., and K. Kiviniemi. 1968. Control of granulocyte production. I. Chalone and antichalone, two specific humoral regulators. Cell Tissue Kinet. 1: 329.

43. Paran, M., Y. Ichikawa, and L. Sachs. 1968. Feedback inhibition of the development of macrophage and granulocyte colonies. II. Inhibition by granulocytes. Proc. Natl. Acad. Sci. U. S. A. 62: 81.

44. Dale, D. C., C. H. Brown, P. Carbone, and S. M. Wolff. 1971. Cyclic urinary leukopoietic activity in gray collie dogs. Science (Wash. D. C.). 173: 152.

45. Adamson, J. W., D. C. Dale, and R. Elin. 1973. Regulation of cyclic erythropoiesis in the grey collie. $J$. Clin. Invest. 52: 1a. (Abstr.)

46. Dale, D. C., and R. G. Graw, Jr. 1974. Transplantation of allogeneic bone marrow in canine cyclic neutropenia. Science (Wash. D. C.). In press. 